\title{
Phthalocyanine and Metal Phthalocyanines Adsorbed on Graphene: A Density Functional Study
}

Siqi Feng, ${ }^{1}$ Ningjing Luo, ${ }^{1}$ Anwen Tang, ${ }^{1}$ Wenjie Chen, ${ }^{1}$ Yongfan Zhang, ${ }^{1,3}$ Shuping Huang, ${ }^{1,3 *}$ Weidong Dou ${ }^{2 *}$

${ }^{1}$ College of Chemistry, Fuzhou University, Fuzhou, Fujian, 350108, China

${ }^{2}$ Physics Department, Shaoxing University, Shaoxing, 312000, China

${ }^{3}$ Fujian Provincial Key Laboratory of Theoretical and Computational Chemistry, Xiamen, Fujian, 361005, China

*E-mail: huangshp@gmail.com (S. Huang)

phyth@usx.edu.cn (W. Dou)

Table of contents

page

Figure S1

S2

Figure S2

S3

Figure S3

S4

Figure S4

S5

Figure S5

S6

Figure S6

S7

Figure S7

S8

References

S9 


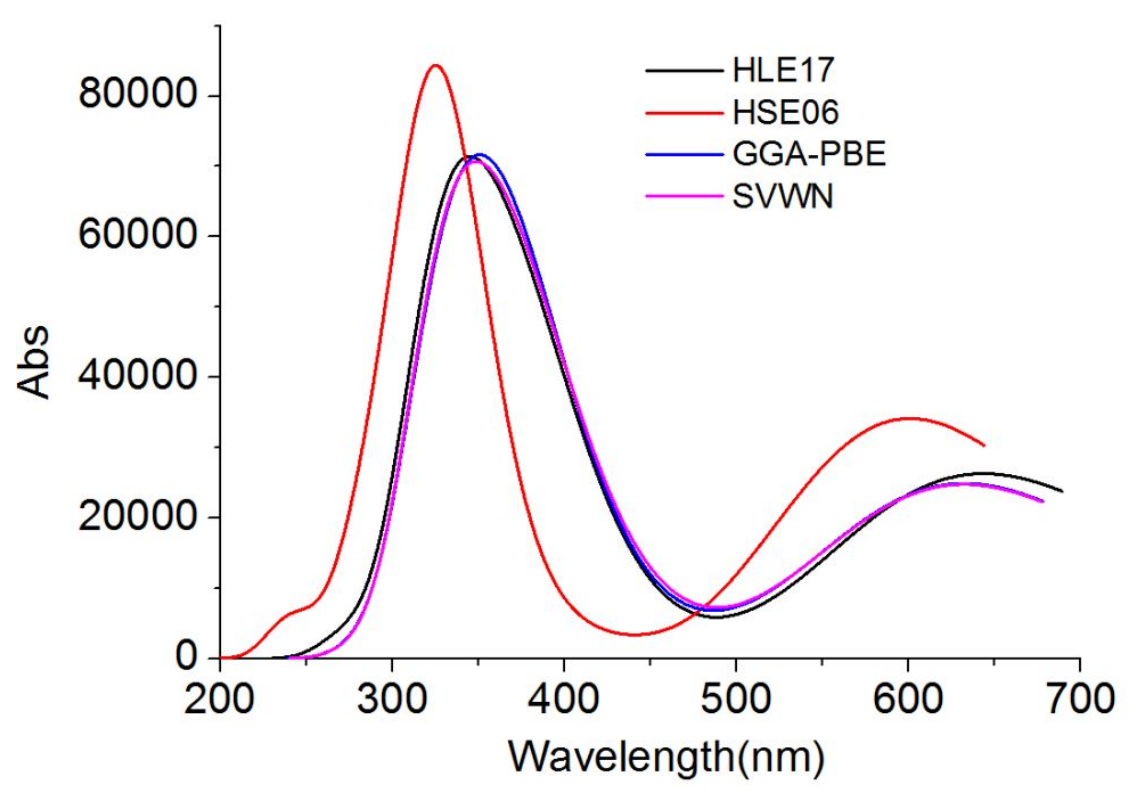

Figure $\mathrm{S} 1$ The calculated absorption spectra for $\mathrm{H}_{2} \mathrm{Pc}$ by several density functionals using Gaussian09. ${ }^{1}$ The 6-31G(d,p) basis sets are used for $\mathrm{C}, \mathrm{H}$, and $\mathrm{N}$ atoms. The calculated absorption peaks between $300 \sim 400 \mathrm{~nm}$ and between $600 \sim 700 \mathrm{~nm}$ by HLE17, GGA-PBE, and SVWN are more close to the experimental ones (See Figure 6D of Ref. 2, the UV-Vis absorption spectrum of the $\mathrm{H}_{2} \mathrm{Pc}$ thin film) than the one by HSE06. The calculated HOMO-LUMO gaps by HLE17, GGA-PBE, SVWN, and HSE06 are 1.36, $1.40,1.39$, and $1.70 \mathrm{eV}$, respectively. 

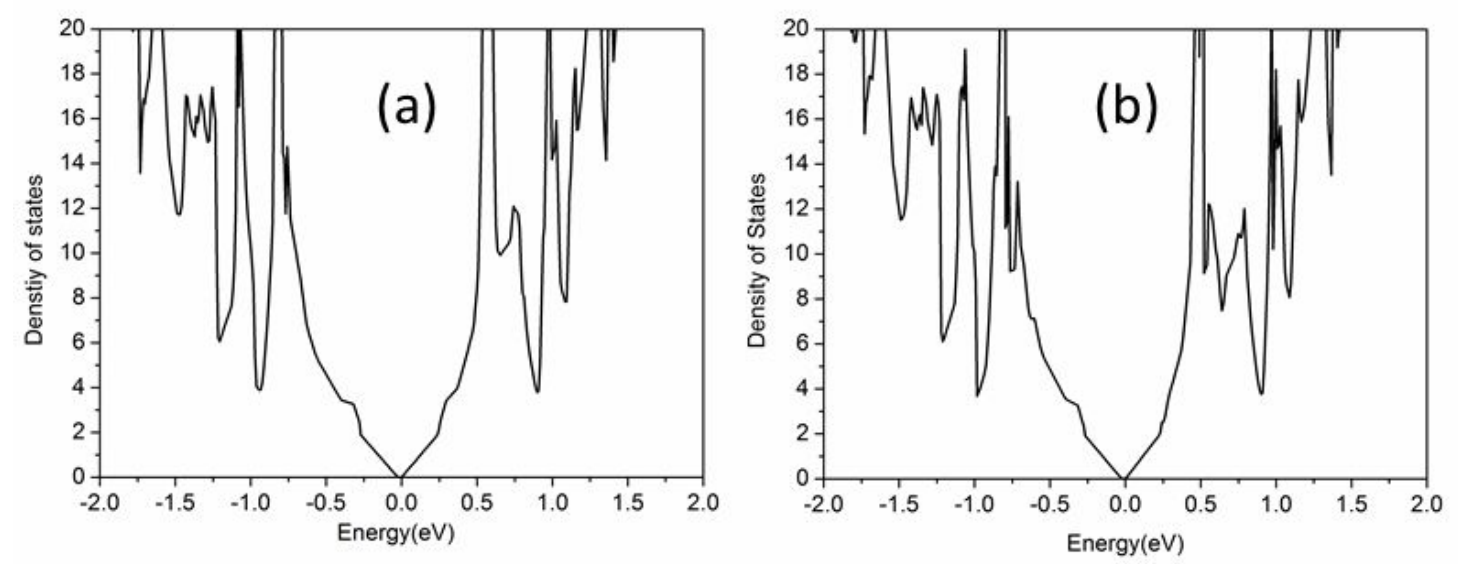

Figure S2 The total density of states of (a) graphene-ZnPc and (b) graphene- $\mathrm{H}_{2} \mathrm{Pc}$. 


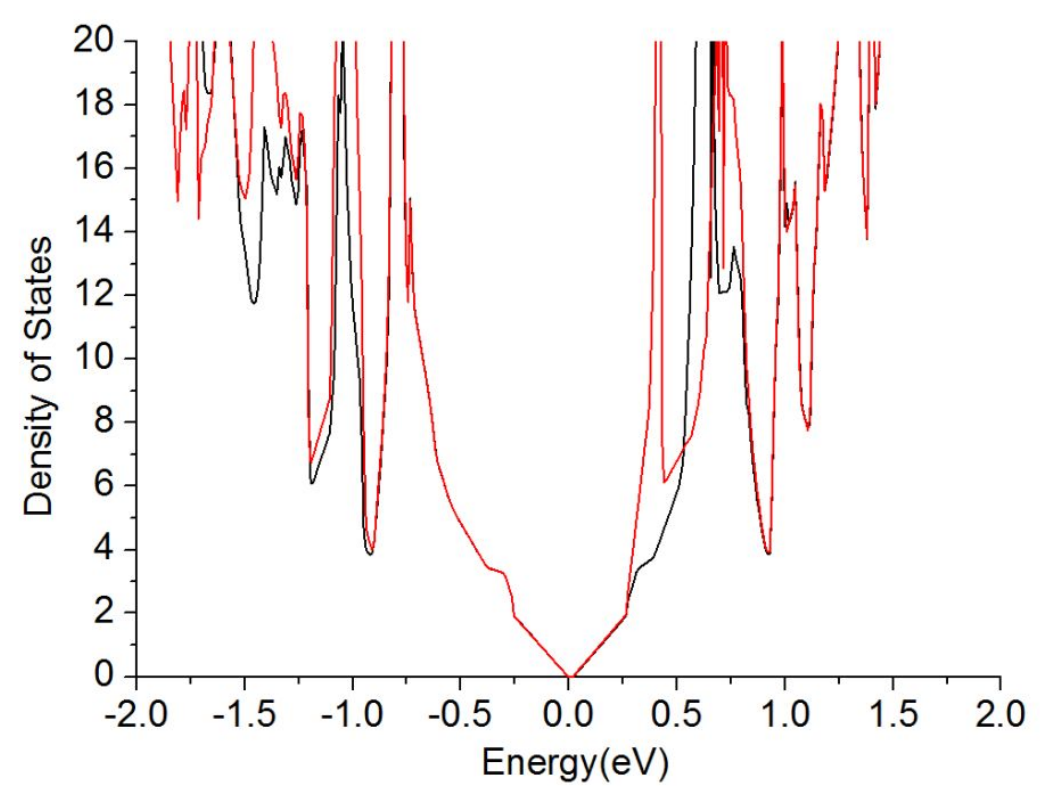

(a)

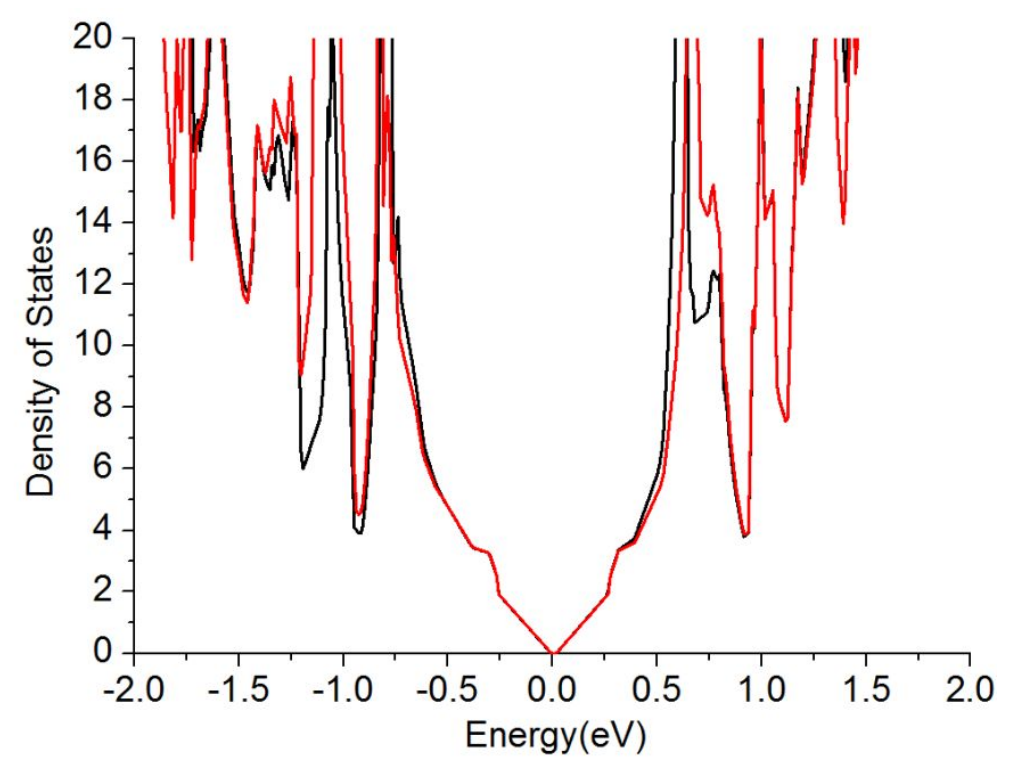

(b)

Figure S3 The total density of states of graphene-FePc by (a) LDA+U and (b) PBE+U, in which the magnetic moment of $\mathrm{Fe}$ is $2 \mu \mathrm{B}$. The black curves are for the majority spin; by convention, this is the $\alpha$ spin (spin up). The red curves are for the minority spin; by convention, this is the $\beta$ spin (spin down). 


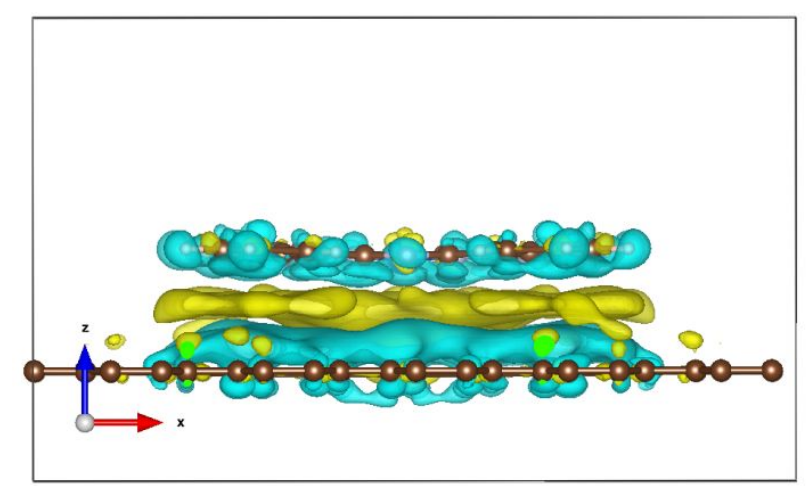

(a)

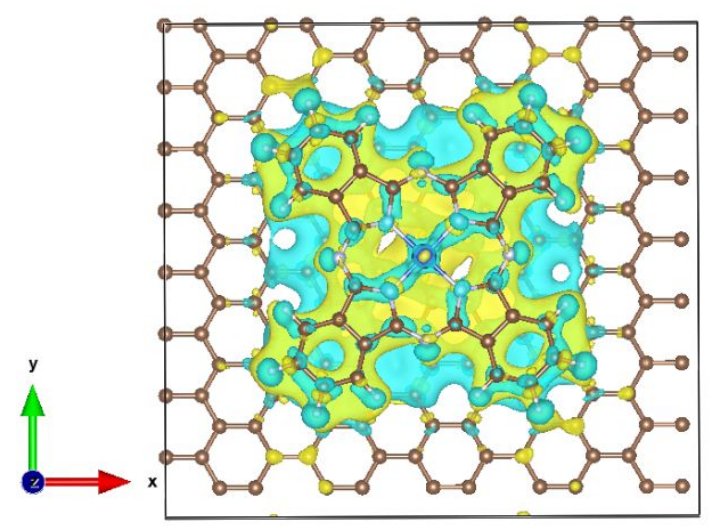

(b)

Figure S4: (a) The side view and (b) the top view of the charge density difference for graphene-CuPc by LDA+U. The isosurface level of the charge density difference is set to $0.00003 \mathrm{e} / \AA^{3}$. 

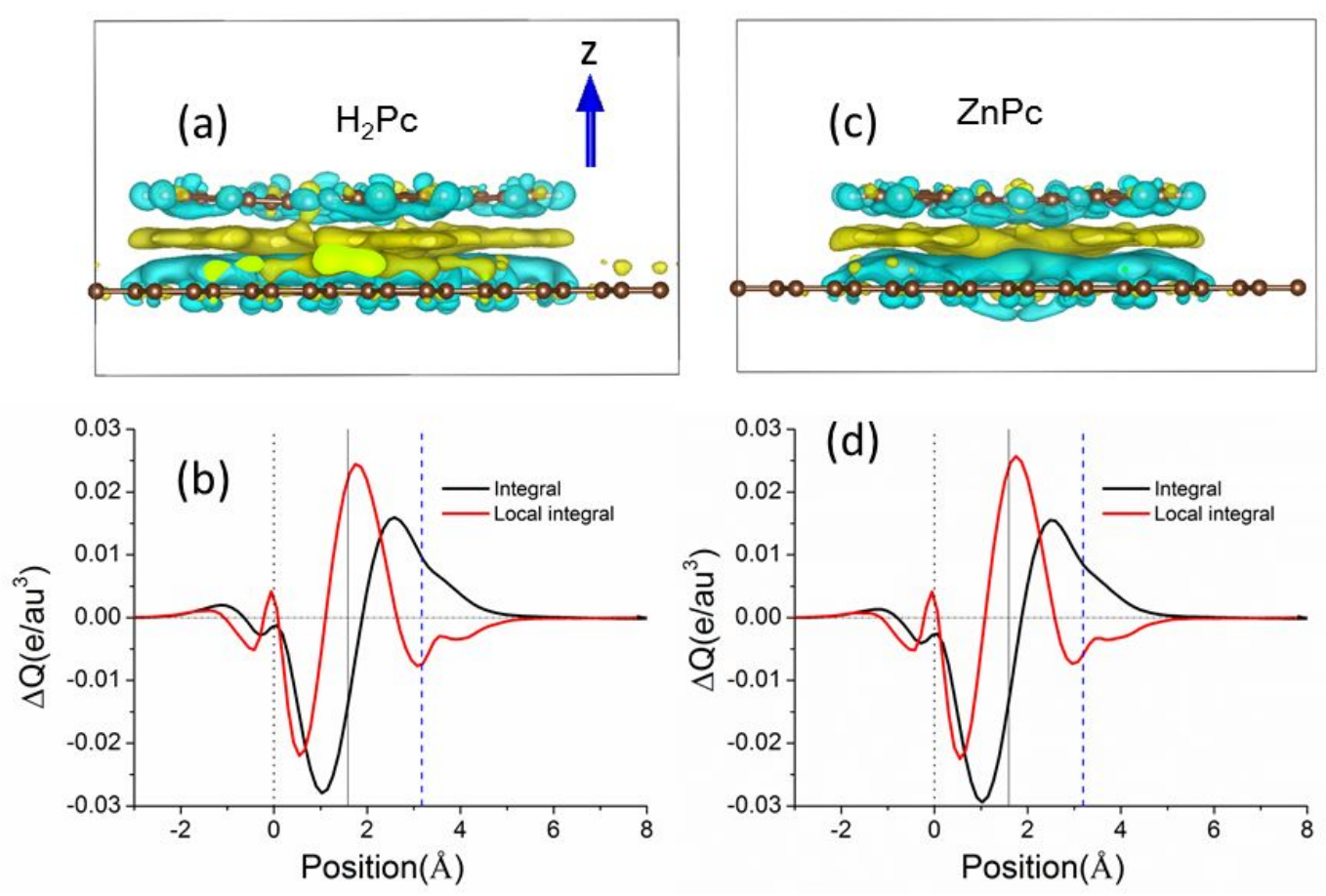

Figure S5 (a) The side view of the charge density difference, (b) local integral curve and integral curve as a function of $\mathrm{z}$ for graphene- $\mathrm{H}_{2} \mathrm{Pc}$. (c) The side view of the charge density difference, (d) local integral curve and integral curve as a function of $\mathrm{z}$ for Graphene-ZnPc. The integral is defined as: $\Delta \mathrm{Q}(\mathrm{z})=\int_{-\infty}^{+\infty} d x \int_{-\infty}^{+\infty} d y \int_{0}^{z} \Delta \rho\left(x, y, z^{\prime}\right) d z^{\prime}$. Yellow (Blue) color indicates charge accumulation (depletion) region. The isosurface level of the charge density difference in (a) and (c) is set to 0.00003 e/ $\AA^{3}$. The dot line at $0 \AA$ is the position of the graphene plane, the dash line at $3 \sim 4 \AA$ is the position of the Pc plane, and the solid line which is in the middle of the dot and dash lines is the interface of graphene and MPc. 

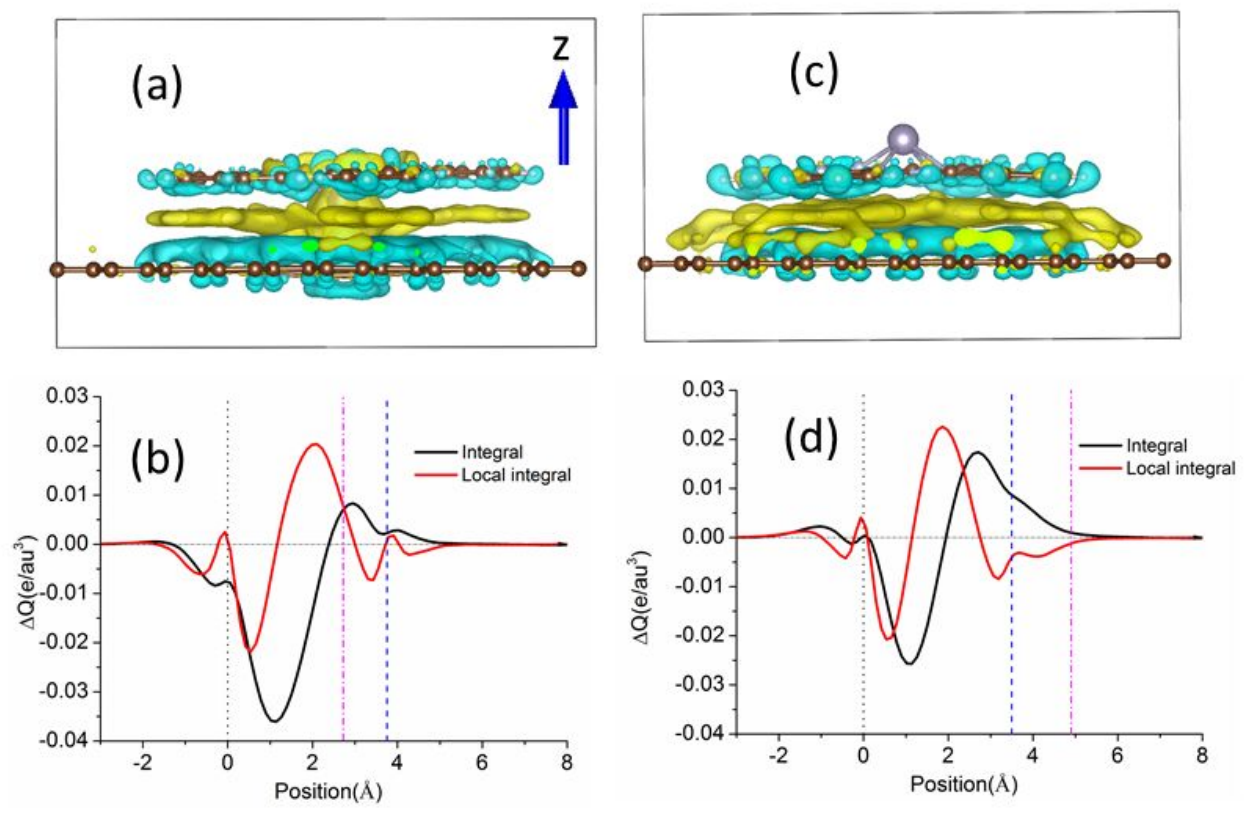

Figure S6 (a) The side view of the charge density difference, (b) local integral curve and integral curve as a function of $\mathrm{z}$ for graphene-SnPc (Sn down). (c) The side view of the charge density difference, (d) local integral curve and integral curve as a function of $\mathrm{z}$ for graphene-SnPc(Sn up). Yellow (Blue) color indicates charge accumulation (depletion) region. The isosurface level of the charge density difference in (a) and (c) is set to $0.00003 \mathrm{e} / \AA^{3}$. The dot line at $0 \AA$ is the position of the graphene plane, the dash line at $3 \sim$ $4 \AA$ is the position of SnPc plane, and the purple dash dot line is the position of Sn. The integral is defined as: $\Delta \mathrm{Q}(\mathrm{z})=\int_{-\infty}^{+\infty} d x \int_{-\infty}^{+\infty} d y \int_{0}^{z} \Delta \rho\left(x, y, z^{\prime}\right) d z^{\prime}$. 

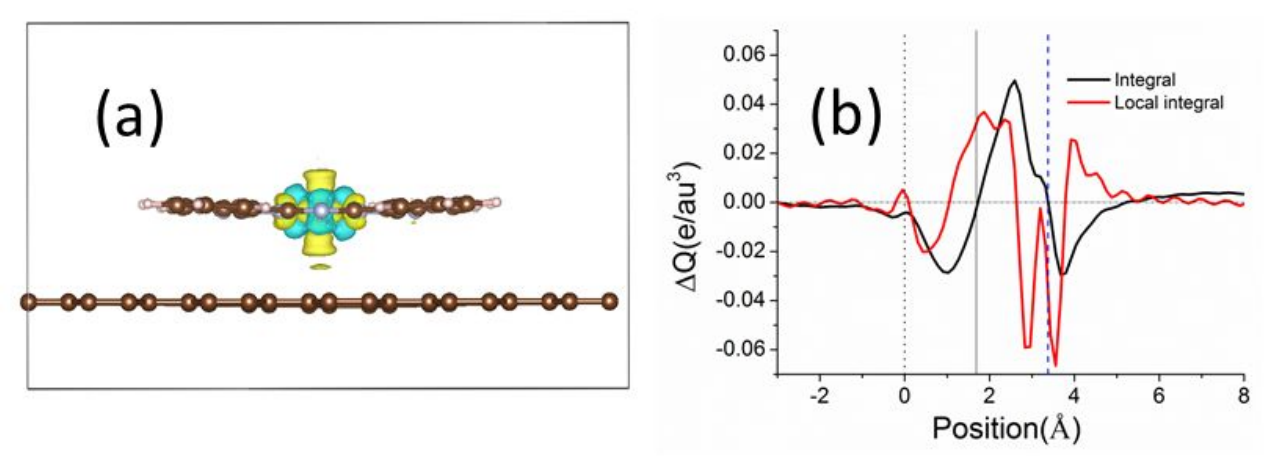

Figure S7 (a) The side view of the charge density difference and (b) local integral curve as a function of $\mathrm{z}$ for graphene-FePc, in which the $\mathrm{Fe}$ is in high spin state. Yellow (Blue) color indicates charge accumulation (depletion) region. The isosurface level of the charge density difference in (a) is set to $0.0008 \mathrm{e} / \AA^{3}$. The dot line at $0 \AA$ is the position of the graphene plane, the dash line at $3 \sim 4 \AA$ is the position of the FePc plane, and the solid line which is in the middle of the dot and dash lines is the interface of graphene and FePc. 
1. Frisch, M. J.; Trucks, G. W.; Schlegel, H. B.; Scuseria,G. E.; Robb, M. A.; Cheeseman, J. R.; Scalmani, G.; Barone, V.; Mennucci, B.; Petersson, G. A.; Nakatsuji, H.; Caricato, M.; Li, X.; Hratchian, H. P.; Izmaylov, A. F.; Bloino, J.; Zheng, G.; Sonnenberg, J. L.; Hada, M.; Ehara, M.; Toyota, K.; Fukuda, R.; Hasegawa, J.; Ishida, M.; Nakajima, T.; Honda, Y.; Kitao, O.; Nakai, H.; Vreven, T.; Montgomery, J. A.; Peralta, Jr., J. E.; Ogliaro, F.; Bearpark, M.; Heyd, J. J.; Brothers, E.; Kudin, K. N.; Staroverov, V. N.; Keith, T.; Kobayashi, R.; Normand, J.; Raghavachari, K.; Rendell, A.; Burant, J. C.; Iyengar, S. S.; Tomasi, J.; Cossi, M.; Rega, N.; Millam, J. M.; Klene, M.; Knox, J. E.; Cross, J. B.; Bakken, V.; Adamo, C.; Jaramillo, J.; Gomperts, R.; Stratmann, R. E.; Yazyev, O.; Austin, A. J.; Cammi, R.; Pomelli, C.; Ochterski, J. W.; Martin, R. L.; Morokuma, K.; Zakrzewski, V. G.; Voth, G. A.; Salvador, P.; Dannenberg, J. J.; Dapprich, S.; Daniels, A. D.; Farkas, O.; Foresman, J. B.; Ortiz, J. V.; Cioslowski, J.; Fox, D. J. Gaussian, Inc., Wallingford CT, 2013.

2. Huang, K. J.; Hsiao, Y. S.; Huang, J. H.; Chu, C. W.; Chen P.; Whang, W. T. Controlling Vertical Alignment of Phthalocyanine Nanofibers on Transparent Graphene-Coated ITO Electrodes for Organic Field Emitters. J. Mater. Chem. 2012, 22, 7837-7844. 